\title{
COVID-19 SEVERE PNEUMONIA: PROSPECTIVE MULTICENTRE STUDY ON DEMANDS ON INTENSIVE CARE CAPACITIES
}

\author{
Olga Džupová1, Michal Moravec ${ }^{2}$, Hynek Bartoš ${ }^{3}$, Peter Brestovanský4, Tomáš Tencer ${ }^{5}$, Tomáš Hyánek ${ }^{6}$,

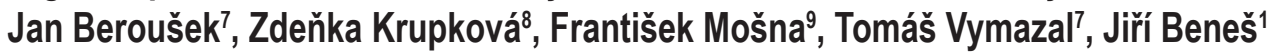 \\ ${ }^{1}$ Third Faculty of Medicine, Charles University, and Department of Infectious Diseases, Hospital Na Bulovce, Prague, Czech Republic \\ ${ }^{2}$ First Faculty of Medicine, Charles University, and Department of Anaesthesiology and Critical Care, Thomayer Hospital, Prague, Czech Republic \\ ${ }^{3}$ Third Faculty of Medicine, Charles University, and Department of Infectious Diseases, Masaryk Hospital, Ústí nad Labem, Czech Republic \\ ${ }^{4}$ First Faculty of Medicine, Charles University, and Department of Anaesthesiology, Resuscitation and Intensive Medicine, General University \\ Hospital, Prague, Czech Republic \\ ${ }^{5}$ Third Faculty of Medicine, Charles University, and Department of Anaesthesiology, Resuscitation and Intensive Medicine, University Hospital \\ Královské Vinohrady, Prague, Czech Republic \\ ${ }^{6}$ Department of Anaesthesiology and Reanimation, Hospital Na Homolce, Prague, Czech Republic \\ ${ }^{7}$ Second Faculty of Medicine, Charles University, and Department of Anaesthesiology, Resuscitation and Intensive Medicine, Motol University \\ Hospital, Prague, Czech Republic \\ ${ }^{8}$ Department of Anaesthesiology and Resuscitation, Hospital Na Bulovce, Prague, Czech Republic \\ ${ }^{9}$ Second Faculty of Medicine, Charles University, and Department of Cardiology, Motol University Hospital, Prague, Czech Republic
}

\section{SUMMARY}

Objectives: The aim of the study was to obtain data on demands on the intensive care capacities to treat COVID-19 patients, and to identify predictors for in-hospital mortality.

Methods: The prospective observational multicentre study carried out from 1 March till 30 June 2020 included adult patients with confirmed SARS-CoV-2 infection with respiratory failure requiring ventilatory support or high-flow nasal oxygen therapy (HFNO).

Results: Seventy-four patients, 46 males and 28 females, median age 67.5 (Q1-Q3: 56-75) years, were included. Sixty-four patients (86.5\%) had comorbidity. Sixty-six patients (89.2\%) were mechanically ventilated, four of them received extracorporeal membrane oxygenation therapy. Eight patients (10.8\%) were treated with non-invasive ventilation and HFNO only. The median of intensive care unit (ICU) stay was 22.5 days. Eighteen patients (24.3\%) needed continuous renal replacement therapy. Thirty patients (40.5\%) died. Age and acute kidney injury were identified as independent predictors of in-hospital death, and chronic kidney disease showed trend towards statistical significance for poor outcome.

Conclusions: Sufficient number of intensive care beds, organ support equipment and well-trained staff is a decisive factor in managing the COVID-19 epidemic. The study focused on the needs of intensive care in the COVID-19 patients. Advanced age and acute kidney injury were identified as independent predictors for in-hospital mortality. When compared to clinical course and ICU management of patients with severe community-acquired pneumonia caused by other pathogens, we observed prolonged need for ventilatory support, high rate of progression to acute respiratory distress syndrome and significant mortality in studied population.

Key words: COVID-19, respiratory failure, kidney disease, intensive care, mortality

Address for correspondence: O. Džupová, Department of Infectious Diseases, Hospital Na Bulovce, Budínova 2, 18081 Prague, Czech Republic. E-mail: olga.dzupova@lf3.cuni.cz

https://doi.org/10.21101/cejph.a6672

\section{INTRODUCTION}

Experience from the course of the COVID-19 epidemic in China, northern Italy, New York and elsewhere has shown that a critical factor for managed epidemics is the availability of intensive care beds, including adequate staffing. The in-hospital mortality of COVID-19 patients treated in intensive care units (ICU) in these regions were 53,62 , and $78 \%$, respectively (1-3). That is much higher than data from following studies reporting mortality of 31 and $39 \%$, respectively $(4,5)$. This correlates with reports of congestion and disintegration of the health system in the above-mentioned areas. Thus, these figures were a memento for all governments in the world to prevent the development of an exponential, uncontrolled epidemic. The aim of our study was to describe a cohort of patients with respiratory failure due to COVID-19, to obtain data on the type and extent of intensive care support and to evaluate the overall cohort mortality. The secondary outcome was to identify predictors for in-hospital mortality in these patients. 


\section{MATERIALS AND METHODS}

The prospective observational multicentre study was carried out at the beginning of SARS CoV-2 epidemic in the Czech Republic between 1 March and 30 June 2020 in nine ICUs in the capital city of Prague and the regional city of Ústí nad Labem, including the adjacent areas, which represents a catchment area of more than 2 million inhabitants, one fifth of the population of the country.

The study included patients who met all inclusion criteria: SARS-CoV-2 infection with viral RNA detected in the airway specimen, admission to intensive care unit, respiratory failure meeting acute respiratory distress syndrome (ARDS) Berlin definition criteria (6) requiring advanced ventilatory/oxygenation support: non-invasive ventilation (NIV), mechanical ventilation (MV), extracorporeal membrane oxygenation (ECMO), or highflow nasal oxygen therapy (HFNO). Exclusion criteria were defined as age $<18$ years and untraceable data from the history and admission (patients transferred from other facilities).

Demographic data, chronic comorbid conditions, clinical and laboratory parameters throughout the ICU and hospital stay, complications, treatment, and clinical outcome were observed.

The study was approved by the Local Ethics Committee of Hospital Na Bulovce (ref. number 26.3.2020/9478/EK-Z).

\section{Statistical Analysis}

Continuous data are characterized by medians and 1st and 3rd quartile (Q1, Q3), categorical data are presented as counts and percentages. Between-group comparisons were performed by Mann-Whitney test and Fisher's exact test for continuous and categorical data, respectively. Multiple logistic regression model yielding odds ratio (OR) as a measure of association was used to identify predictors of in-hospital mortality. All statistical tests were evaluated at a significance level of 0.05 .

\section{RESULTS}

The study included 74 patients aged 35-87 years with a median of 67.5 (Q1-Q3: 56-75) years. No patient was excluded based on the exclusion criteria. Table 1 shows patient characteristics, complications, and treatment outcomes. Sixty-four patients $(86.5 \%)$ suffered from an underlying chronic disease, most often hypertension and diabetes.

All patients had bilateral pulmonary infiltrates corresponding with interstitial pneumonia on an admission chest X-ray. Twentyfive of them (33.8\%) were admitted with hypoxemic respiratory failure, 27 (36.5\%) developed hypoxemia within 72 hours after admission. The initial $\mathrm{paO}_{2} / \mathrm{FiO}_{2}$ ratio at the beginning of ventilatory support or the lowest $\mathrm{paO}_{2} / \mathrm{FiO}_{2}$ ratio on ventilatory/oxygenation support met the criteria for moderate to severe ARDS. Sixty-six patients $(89.2 \%)$ were mechanically ventilated, four of them later required ECMO therapy. Eight patients (10.8\%) were treated with NIV and HFNO only. Intensive care data are shown in Table 2.

Antiviral therapy was given in accordance with the guidelines in force at the time. The most commonly used drug was hydroxychloroquine with or without azithromycin. Seven patients were treated with convalescent plasma.
Table 1. Patient characteristics, complications, and treatment outcomes $(N=74)$

\begin{tabular}{|c|c|}
\hline & $\mathrm{n}(\%)$ \\
\hline Age (years) (Q1-Q3) & $67.5(56-75)$ \\
\hline Men & $46(62.2)$ \\
\hline \multicolumn{2}{|l|}{ Comorbidities } \\
\hline Any comorbidity (excl. obesity, smoking) & $64(86.5)$ \\
\hline Lung disease (COPD, asthma, others) & $17(23.0)$ \\
\hline COPD only & $7(9.5)$ \\
\hline Immune deficiency & $6(8.1)$ \\
\hline ACE inhibitors & $18(24.3)$ \\
\hline Diabetes & $30(40.5)$ \\
\hline Hypertension & $48(64.9)$ \\
\hline Coronary heart disease & $16(21.6)$ \\
\hline Chronic kidney disease & $10(13.5)$ \\
\hline Chronic liver disease & $5(6.8)$ \\
\hline Cancer disease & $7(9.5)$ \\
\hline $\mathrm{BMI}\left(\mathrm{kg} / \mathrm{m}^{2}\right)(\mathrm{Q} 1-\mathrm{Q} 3)$ & $31(27-37)$ \\
\hline $\mathrm{BMl}>30$ & $40(54.1)$ \\
\hline $\mathrm{BMl}>35$ & $21(28.4)$ \\
\hline \multirow[t]{2}{*}{ Current smoking } & $20(27.0)$ \\
\hline & Median (Q1-Q3) \\
\hline Time symptoms onset to admission (days) & $6(4-8)$ \\
\hline Time admission to ventilation support (days) & $1(0-4)$ \\
\hline \multicolumn{2}{|l|}{ At the admission } \\
\hline Oxygen saturation $(\%)$ & $88(80-91)$ \\
\hline Oxygen saturation < $<0 \%, \mathrm{n}(\%)$ & $48(64.9)$ \\
\hline CURB-65 & $2(1-3)$ \\
\hline Leukocytes $\left(\times 10^{3}\right.$ per $\left.\mathrm{mm}^{3}\right)$ & $7.5(5.9-12.2)$ \\
\hline Lymphocytes $\left(\times 10^{3}\right.$ per mm $\mathrm{mm}^{3}$ & $0.8(0.6-1.1)$ \\
\hline Neutrophil/lymphocyte ratio & $9.2(4.9-12.9)$ \\
\hline Platelets $\left(\times 10^{3}\right.$ per $\left.\mathrm{mm}^{3}\right)$ & $210(164-267)$ \\
\hline $\mathrm{CRP}(\mathrm{mg} / \mathrm{L})$ & $117(71-169)$ \\
\hline PCT (ng/mL) & $0.17(0.11-0.60)$ \\
\hline Urea (mmol/L) & $7.2(4.8-11.1)$ \\
\hline \multicolumn{2}{|l|}{ At the onset of ventilation support } \\
\hline Leukocytes $\left(\times 10^{3}\right.$ per $\left.\mathrm{mm}^{3}\right)$ & $10.0(7.5-13.6)$ \\
\hline Lymphocytes $\left(\times 10^{3}\right.$ per mm³) & $0.8(0.5-1.1)$ \\
\hline Neutrophil/lymphocyte ratio & $10.1(6.8-17.6)$ \\
\hline Platelets $\left(\times 10^{3}\right.$ per $\left.\mathrm{mm}^{3}\right)$ & $239(178-303)$ \\
\hline $\mathrm{CRP}(\mathrm{mg} / \mathrm{L})$ & $192(112-267)$ \\
\hline PCT (ng/mL) & $0.38(0.16-0.86)$ \\
\hline $\mathrm{paO}_{2} / \mathrm{FiO}_{2}$ at the onset of ventilation support & $118(91-145)$ \\
\hline $\mathrm{paO}_{2} / \mathrm{FiO}_{2}$ lowest value & $100(77-124)$ \\
\hline PEEP on the day of lowest $\mathrm{paO}_{2} / \mathrm{FiO}_{2}\left(\mathrm{~cm} \mathrm{H}_{2} \mathrm{O}\right)$ & $14(12-14)$ \\
\hline
\end{tabular}

Continued on the next page 
Continued from the previous page

\begin{tabular}{|l|c|}
\hline Complications & $\mathbf{n}(\%)$ \\
\hline Acute respiratory distress syndrome (ARDS) & $57(77.0)$ \\
\hline Respiratory secondary infection & $52(70.3)$ \\
\hline Other system secondary infection & $28(37.8)$ \\
\hline Acute renal failure & $21(28.4)$ \\
\hline Thrombotic event & $7(9.5)$ \\
\hline Outcomes & $31(41.9)$ \\
\hline Discharged home & $13(17.6)$ \\
\hline Transferred to long-term care facility & $30(40.5)$ \\
\hline Died in the hospital & $31.5(15-51)$ \\
\hline $\begin{array}{l}\text { Hospitalisation at the acute-care department } \\
\text { (days) (Q1-Q3) }\end{array}$ & \\
\hline
\end{tabular}

CRP - C-reactive protein; PCT - procalcitonin; PEEP - positive end-expiratory pressure

Table 2. Intensive care delivered to patients with respiratory failure $(N=74)$

\begin{tabular}{|l|c|}
\hline Type of care & $\mathbf{n}(\%)$ \\
\hline Extracorporeal membrane oxygenation $^{\text {a }}$ & $4(5.4)$ \\
\hline Mechanical ventilation $^{\text {a }}$ & $66(89.2)$ \\
\hline Non-invasive ventilation $^{\text {a }}$ & $23(31.1)$ \\
\hline High-flow nasal oxygen therapy $^{\mathrm{a}}$ & $11(14.9)$ \\
\hline Prone-positioning & $40(54.1)$ \\
\hline Vasopressors & $66(89.2)$ \\
\hline Continuous myorelaxants & $16(21.6)$ \\
\hline Renal replacement therapy & $19(25.7)$ \\
\hline Length of care (days) & Median (Q1-Q3) \\
\hline ICU stay & $22.5(12-40)$ \\
\hline MV & $19.5(10-30)$ \\
\hline NIV & $1(1-4)$ \\
\hline HFNO & $2(1-4)$ \\
\hline Vasopressors & $9.5(6-17)$ \\
\hline Continuous myorelaxation & $3.5(2.5-5.5)$ \\
\hline CRRT & $6(3-14)$ \\
\hline Acute care dept. stay of survivors & $43.5(30.5-56)$ \\
\hline
\end{tabular}

aSome patients had multiple forms of ventilatory support.

ICU - intensive care unit; MV - mechanical ventilation; NIV - non-invasive ventilation; HFNO - high-flow nasal oxygen therapy (HFNO); CRRT - continuous renal replacement therapy

The duration of ICU treatment ranged from 1-78 days. Thirty patients $(40.5 \%)$ died, half of them during the first 10 days of admission, most of them due to respiratory failure or multiple organ failure. The median length of MV was 19.5 days, range 1-70 days, 26 days in survivors. Fifty-two patients (70.3\%), all mechanically ventilated, developed hospital-acquired respiratory tract infection (HA-RTI), either ventilator-associated pneumonia (VAP) or tracheobronchitis, and 20 of them died (38.5\%). Ten out of 22 patients without documented HA-RTI $(45.5 \%)$ died. The total length of hospital stay was 1-82 days with a median of 31.5 days, in survivors 43.5 days.

Renal replacement therapy (RRT) was needed in 19 patients (25.7\%), two of them on chronic haemodialysis prior to admission and 17 had acute renal failure; 16 patients received continuous RRT (CRRT), one intermittent haemodialysis and two patients a combination of both techniques.

Seven patients $(9.5 \%)$ had thrombotic complications (pulmonary embolism, arterial or venous thrombosis, ischaemic stroke) and two of them died.

When comparing the group of survivors and nonsurvivors by univariate analysis (Table 3), the following variables were statistically significant: age, hypertension, chronic kidney disease, score CURB-65, urea at admission, and acute renal failure. These variables were further used for a multivariate analysis in which age and acute renal failure emerged as significant independent predictors of in-hospital death; chronic kidney disease remained closely insignificant despite the high odds ratio (Table 4).

\section{DISCUSSION}

The population of the Czech Republic is 10.5 million inhabitants. Our study involved an area with more than 2 million people. However, the incidence of COVID-19 was higher in this area than in other regions. In the study period, 10,908 cases of SARS-CoV-2 infection were detected by PCR testing in the whole country, of which 4,131 (37.9\%) occurred in the studied region; 478 of them were admitted to the hospitals, i.e. $11.6 \%$ of all positive cases in the region*. Patients with respiratory failure accounted for $15.5 \%$ of those hospitalized for SARS-CoV-2 and $1.8 \%$ of all people with confirmed infection in the monitored area.

The first case of COVID-19 in the Czech Republic was reported on 1 March 2020. The vast majority of patients enrolled in our study were admitted during March and April (72 patients) (Fig. 1). Only two more patients were added in May and none in June despite the fact that the initial restrictive measures had been

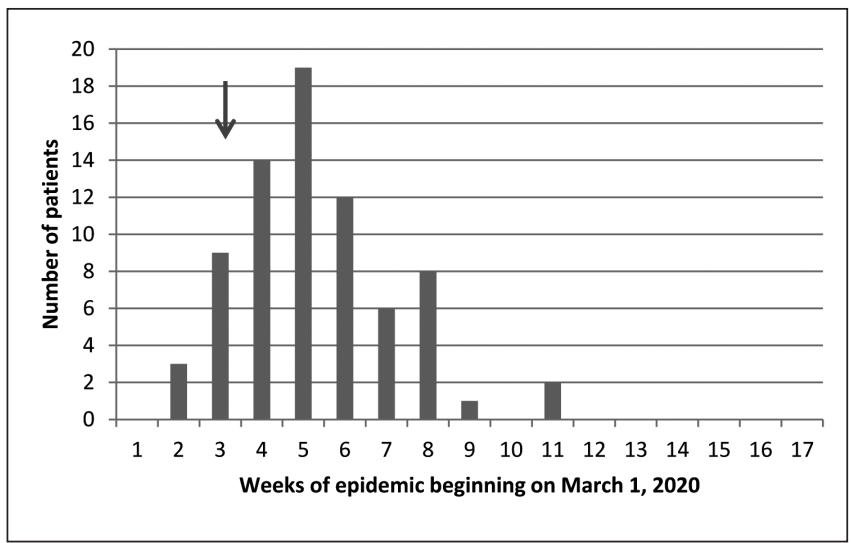

Fig. 1. Number of new COVID-19 patients with respiratory failure.

The arrow indicates the announcement of widespread measures against the spread of the infection (ban on public events, mandatory face masks, closing schools, etc.) It is clear that the number of cases continued to rise for about two more weeks.

*Personal communication, Dr. Jan Kynčl, National Institute of Public Health, Prague; data from the national surveillance system for infectious diseases ISIN. 
Table 3. Comparison of characteristics and outcomes between survivors and nonsurvivors $(N=74)$

\begin{tabular}{|c|c|c|c|}
\hline & $\begin{array}{c}\text { Survivors } \\
(n=44) \\
n(\%)\end{array}$ & $\begin{array}{c}\text { Nonsurvivors } \\
\begin{array}{c}(n=30) \\
n(\%)\end{array}\end{array}$ & $\mathrm{p}$-value \\
\hline Age (years) (Q1-Q3) & $64.5(53-69.5)$ & $74.5(69-79)$ & $<0.001$ \\
\hline Men & $28(63.6)$ & $18(60.0)$ & 0.810 \\
\hline \multicolumn{4}{|l|}{ Comorbidities } \\
\hline Any comorbidity (excl. obesity, smoking) & $36(81.8)$ & $28(93.3)$ & 0.187 \\
\hline Lung disease (COPD, asthma, others) & $10(22.7)$ & $7(23.3)$ & 1.000 \\
\hline COPD only & $2(4.5)$ & $5(16.7)$ & 0.112 \\
\hline ACE inhibitors & $8(18.2)$ & $10(33.3)$ & 0.172 \\
\hline Diabetes & $17(38.6)$ & $13(43.3)$ & 0.810 \\
\hline Hypertension & $24(54.5)$ & $24(80.0)$ & 0.028 \\
\hline Coronary heart disease & $7(15.9)$ & $9(30.0)$ & 0.164 \\
\hline Chronic kidney disease & $1(2.3)$ & $9(30.0)$ & 0.001 \\
\hline $\mathrm{BMI}\left(\mathrm{kg} / \mathrm{m}^{2}\right)(\mathrm{Q} 1-\mathrm{Q} 3)$ & $31(27.5-37)$ & $32.5(26-37)$ & 0.851 \\
\hline $\mathrm{BMI}>30$ & $23(52.3)$ & $17(56.7)$ & 0.814 \\
\hline $\mathrm{BMI}>35$ & $12(27.3)$ & $9(30.0)$ & 0.799 \\
\hline Current smoking & $12(27.3)$ & $8(26.7)$ & 1.000 \\
\hline At the admission & Median (Q1-Q3) & Median (Q1-Q3) & \\
\hline Oxygen saturation (\%) & $88(82-91.5)$ & $86.5(78-90)$ & 0.375 \\
\hline Oxygen saturation $<90 \%, \mathrm{n}(\%)$ & $27(61.4)$ & $21(70.0)$ & 0.470 \\
\hline CURB-65 & $2(0-2.5)$ & $2(2-3)$ & 0.005 \\
\hline Leukocytes $\left(\times 10^{3}\right.$ per $\left.\mathrm{mm}^{3}\right)$ & $7.1(5.9-10.3)$ & $9.0(5.9-13.6)$ & 0.137 \\
\hline Neutrophil/lymphocyte ratio & $9.1(4.9-10.9)$ & $10.4(4.1-17.0)$ & 0.621 \\
\hline Platelets $\left(\times 10^{3}\right.$ per mm $\left.\mathrm{mm}^{3}\right)$ & $213(172-256)$ & $197(163-280)$ & 0.708 \\
\hline $\mathrm{CRP}(\mathrm{mg} / \mathrm{L})$ & $131(85-174)$ & $100(57-153)$ & 0.123 \\
\hline PCT (ng/mL) & $0.16(0.10-0.79)$ & $0.19(0.13-0.52)$ & 0.489 \\
\hline Urea (mmol/L) & $5.8(4.2-9.2)$ & $9.9(6.2-12.8)$ & 0.002 \\
\hline \multicolumn{4}{|l|}{ At the onset of ventilation support } \\
\hline Leukocytes $\left(\mathrm{x} 10^{3}\right.$ per $\left.\mathrm{mm}^{3}\right)$ & $9.7(7.7-12.8)$ & $10.9(6.9-15.1)$ & 0.425 \\
\hline Neutrophil/lymphocyte ratio & $9.7(7.0-15.4)$ & $12.7(6.4-20.8)$ & 0.457 \\
\hline Platelets $\left(\times 10^{3}\right.$ per mm³) & $251(204-316)$ & $230(170-280)$ & 0.186 \\
\hline $\mathrm{CRP}(\mathrm{mg} / \mathrm{L})$ & $207(119-268)$ & $164(97-231)$ & 0.213 \\
\hline PCT (ng/mL) & $0.38(0.16-0.84)$ & $0.40(0.16-1.34)$ & 0.553 \\
\hline $\mathrm{paO}_{2} / \mathrm{FiO}_{2}$ at the onset of ventilation support & $120(89-138)$ & $116(100-150)$ & 0.499 \\
\hline $\mathrm{paO}_{2} / \mathrm{FiO}_{2}$ lowest value & $100(77-130)$ & $98(77-116)$ & 0.427 \\
\hline Complications & $\mathrm{n}(\%)$ & $\mathrm{n}(\%)$ & \\
\hline Respiratory secondary infection & $32(72.7)$ & $20(66.7)$ & 0.612 \\
\hline Other system secondary infection & $21(47.7)$ & $7(23.3)$ & 0.050 \\
\hline Acute renal failure & $6(13.6)$ & $15(50.0)$ & 0.001 \\
\hline
\end{tabular}

COPD - chronic obstructive pulmonary disease; ACE - angiotensin-converting enzyme; CRP - C-reactive protein; PCT - procalcitonin

gradually stepped down since mid-April. The reasons for successful management of the first wave of coronavirus epidemic in the Czech Republic were described by Widimsky et al. (7). It should be emphasized that strict anti-epidemic measures, although taken by people almost immediately after announcement, only had an effect after two weeks, i.e. after about 2-3 times the COVID-19 incubation period.
Most of the patients admitted to ICU required long-term mechanical ventilation, often with vasopressors for associated haemodynamic failure, and half of them were prone positioned. The median length of MV and ICU stay was 2-3 times longer compared to studies of severe pneumonia due to other pathogens with medians ranging 4-8 days for MV and 7-14 days for ICU stay (8-10). More than a quarter of patients required renal replacement therapy, mostly CRRT. 
Table 4. Predictors of in-hospital mortality identified by multiple logistic regression $(N=74)$

\begin{tabular}{|l|c|c|c|}
\hline Variable & OR & $\mathrm{p}$-value & $95 \% \mathrm{Cl}$ \\
\hline Age & 1.13 & 0.002 & $1.05-1.22$ \\
\hline Acute kidney injury & 16.81 & 0.001 & $3.16-89.45$ \\
\hline Chronic kidney disease & 9.99 & 0.056 & $0.95-105.25$ \\
\hline
\end{tabular}

$95 \% \mathrm{Cl}-95 \%$ confidence interval

An unusually high proportion had secondary respiratory tract infection, compared to frequency of VAP $13-18 \%$ reported in medical ICUs $(11,12)$. In COVID-19 patients, Garcia-Vidal et al. and Langford et al. reported the global frequency of secondary infection 4.7 and $14.3 \%$, respectively $(13,14)$. Secondary respiratory infections prolong the need for ventilatory support, and vice versa, the longer mechanical ventilation, the higher the risk for HA-RTI. However, HA-RTI was not associated with higher mortality in our patients. This finding can be explained by the fact that patients dying early in the course of SARS-CoV-2 pneumonia did not get time to develop HA-RTI.

Clinical and laboratory characteristics of our patients correlated with previously published COVID-19 clinical studies (3, 5, 15, 16). Intensive care was needed mainly for older patients aged 56-75 years, more often men with typical chronic medical conditions (hypertension, cardiovascular disease, diabetes, obesity). Lymphopenia, high neutrophil/lymphocyte ratio, high C-reactive protein (CRP) and low procalcitonin (PCT) were common laboratory findings. Interestingly, median PCT level was lower than values 0.56 and $0.62 \mathrm{ng} / \mathrm{ml}$ reported in studies of patients with severe influenza A(H1N1)2009 pneumonia $(17,18)$.

Risk factors such as male gender, hypertension, chronic obstructive pulmonary disease (COPD), obesity, cardiovascular disease, lymphopenia, or low oxygenation, that have been described to associate with severe and critical COVID-19 (1, 2, 16), were not found being significant predictors of death in this specific group of patients, as their proportion was similarly high in both survivors and nonsurvivors. By multivariate analysis, we have identified two independent predictors of mortality: age and acute kidney injury (AKI). Chronic kidney disease is likely to reach statistical significance if more patients were enrolled.

The significance of age as a risk factor for severe to critical course of COVID-19 and death was described in the early clinical studies focused on this disease $(11,16,19)$. In our patients, the odds of death increased by $13 \%$ with each additional year of age.

The association of acute renal failure with COVID-19 is an interesting phenomenon. The first studies reported low incidence of AKI complicating COVID-19 disease (20-22), and only recently more papers describing the relationship were published (2, 23-25). The pathogenesis of renal injury is still poorly understood, probably a combination of several different mechanisms occurs: direct pathogenic effect of the virus on proximal tubule cells $(26,27)$; cytokine storm with associated hypoperfusion and multiple organ dysfunction; hypoxia due to pneumonia; the effect of administered drugs; and others $(28,29)$. Our data also show the association of AKI with higher mortality. This is not surprising, because AKI is generally known risk factor for adverse outcome in critically ill. However, there is also an obvious reverse association: a chronic kidney disease worsens the prognosis of COVID-19.

The most common cause of death in the early stages of ICU admission was respiratory failure or multiple organ failure caused by coronavirus infection. On the contrary, death after day 10 of hospital stay was most often caused by persisting ARDS, secondary infections or other severe complications of prolonged critical illness.

There are several strengths of our study. It is the first and so far, the only clinical study from the Czech Republic on severe to critical COVID-19. It reports the findings from a Central European country that suffered from a lower burden of the first wave SARS-CoV-2 pandemic compared to other European countries. The prospective design enabled us to collect all the anamnestic, clinical and laboratory data at the point of enrolment and then throughout the ICU and hospital stay, and therefore, almost no data were lost. Our findings may have an important impact on future planning of health care system capacity in any country.

\section{CONCLUSIONS}

The capacity of intensive care beds is limited in every country. Moreover, patients with severe to critical course of COVID-19 need complex and long-term intensive care with ventilatory and another organ support. Advanced age and acute kidney injury were identified as independent predictors for in-hospital mortality. Therefore, the lesson for other epidemics of respiratory viral infections is to manage the intensive care capacity very carefully, and to count specifically with the high need for ventilators, ECMO and CRRT therapy, and prolonged stay in ICU. Last but not least, it is advisable in quiet times to train medical staff in the organ support management in isolation environment and appropriate use of personal protective equipment. When qualified doctors and nurses fall ill, no one can replace them.

\section{Acknowledgement}

The authors thank RNDr. Marek Malý for statistical analysis, Jan Kynčl, $\mathrm{MD}, \mathrm{PhD}$, for epidemiological data, and RNDr. Dana Nováková for help in collecting literature.

The study was supported by the Ministry of Health of the Czech Republic grant for development of research institution, $\mathrm{MH} \mathrm{CZ}$ - DRO (Thomayer Hospital - TN, 00064190).

\section{Conflict of Interests}

None declared

\section{REFERENCES}

1. Grasselli G, Greco M, Zanella A, Albano G, Antonelli M, Bellani $\mathrm{G}$, et al. Risk factors associated with mortality among patients with COVID-19 in intensive care units in Lombardy, Italy. JAMA Intern Med. 2020;180(10):1345-55.

2. Yang X, Jin Y, Li R, Zhang Z, Sun R, Chen D. Prevalence and impact of acute renal impairment on COVID-19: a systematic review and metaanalysis. Crit Care. 2020;24(1):356. doi: 10.1186/s13054-020-03065-4. 
3. Richardson S, Hirsch JS, Narasimhan M, Crawford JM, McGinn T, Davidson KW, et al. Presenting characteristics, comorbidities, and outcomes among 5700 patients hospitalized with COVID-19 in the New York City area. JAMA. 2020;323(20):2052-9.

4. Auld SC, Caridi-Scheible M, Blum JM, Robichaux C, Kraft C, Jacob JT, et al. ICU and ventilator mortality among critically ill adults with coronavirus disease 2019. Crit Care Med. 2020;48(9):e799-804.

5. Cummings MJ, Baldwin MR, Abrams D, Jacobson SD, Meyer BJ, Balough EM, et al. Epidemiology, clinical course, and outcomes of critically ill adults with COVID-19 in New York City: a prospective cohort study. Lancet. 2020;395(10239):1763-70.

6. ARDS Definition Task Force. Acute respiratory distress syndrome: the Berlin Definition. JAMA. 2012;307(23):2526-33.

7. Widimsky P, Benes J, Celko AM. Czech Republic and low COVID-19 mortality in the heart of Europe: possible explanations. Eur Heart J. 2020;41(40):3876-9.

8. Erdem H, Turkan H, Cilli A, Karakas A, Karakurt Z, Bilge U, et al. Mortality indicators in community-acquired pneumonia requiring intensive care in Turkey. Int J Infect Dis. 2013;17(9):e768-72.

9. Pereira JM, Goncalves-Pereira J, Ribeiro O, Baptista JP, Froes F, Paiva JA. Impact of antibiotic therapy in severe community-acquired pneumonia: data from the Infauci study. J Crit Care. 2018;43:183-9.

10. Walden AP, Clarke GM, McKechnie S, Hutton P, Gordon AC, Rello J, et al. Patients with community acquired pneumonia admitted to European intensive care units: an epidemiological survey of the GenOSept cohort. Crit Care. 2014;18(2):R58. doi: 10.1186/cc13812.

11. Blot S, Koulenti D, Dimopoulos G, Martin C, Komnos A, Krueger WA, et al. Prevalence, risk factors, and mortality for ventilator-associated pneumonia in middle-aged, old, and very old critically ill patients. Crit Care Med. 2014;42(3):601-9.

12. Koulenti D, Tsigou E, Rello J. Nosocomial pneumonia in 27 ICUs in Europe: perspectives from the EU-VAP/CAP study. Eur J Clin Microbiol Infect Dis. 2017;36(11):1999-2006.

13. Garcia-Vidal C, Sanjuan G, Moreno-García E, Puerta-Alcalde P, GarciaPouton N, Chumbita M, et al. Incidence of co-infections and superinfections in hospitalized patients with COVID-19: a retrospective cohort study. Clin Microbiol Infect. 2021;27(1):83-8.

14. Langford BJ, So M, Raybardhan S, Leung V, Westwood D, MacFadden $\mathrm{DR}$, et al. Bacterial co-infection and secondary infection in patients with COVID-19: a living rapid review and meta-analysis. Clin Microbiol Infect. 2020;26(12):1622-9.

15. Grasselli G, Zangrillo A, Zanella A, Antonelli M, Cabrini L, Castelli A, et al. Baseline characteristics and outcomes of 1591 patients infected with SARS-CoV-2 admitted to ICUs of the Lombardy region, Italy. JAMA. 2020;323(16):1574-81.

16. Zhou F, Yu T, Du R, Fan G, Liu Y, Liu Z, et al. Clinical course and risk factors for mortality of adult inpatients with COVID-19 in Wuhan, China: a retrospective cohort study. Lancet. 2020;395(10229):1054-62.

17. Pfister R, Kochanek M, Leygeber T, Brun-Buisson C, Cuquemelle E, Machado MB, et al. Procalcitonin for diagnosis of bacterial pneumonia in critically ill patients during $2009 \mathrm{H} 1 \mathrm{~N} 1$ influenza pandemic: a prospective cohort study, systematic review and individual patient data meta-analysis. Crit Care. 2014;18(2):R44. doi: 10.1186/cc13760.

18. Ingram PR, Inglis T, Moxon D, Speers D. Procalcitonin and C-reactive protein in severe $2009 \mathrm{H} 1 \mathrm{~N} 1$ influenza infection. Intensive Care Med. 2010;36(3):528-32.

19. Zangrillo A, Beretta L, Scandroglio AM, Monti G, Fominskiy E, Colombo S, et al. Characteristics, treatment, outcomes and cause of death of invasively ventilated patients with COVID-19 ARDS in Milan, Italy. Crit Care Resusc. 2020;22(3):200-11.

20. Chen YT, Shao SC, Hsu CK, Wu IW, Hung MJ, Chen YC. Incidence of acute kidney injury in COVID-19 infection: a systematic review and metaanalysis. Crit Care. 2020;24(1):346. doi: 10.1186/s13054-020-03009-y.

21. Wang D, Hu B, Hu C, Zhu F, Liu X, Zhang J, et al. Clinical characteristics of 138 hospitalized patients with 2019 novel coronavirus-infected pneumonia in Wuhan, China. JAMA. 2020;323(11):1061-9.

22. Wang L, Li X, Chen H, Yan S, Li D, Li Y, et al. Coronavirus disease 19 infection does not result in acute kidney injury: an analysis of 116 hospitalized patients from Wuhan, China. Am J Nephrol. 2020;51(5):343-8.

23. Cheng Y, Luo R, Wang K, Zhang M, Wang Z, Dong L, et al. Kidney disease is associated with in-hospital death of patients with COVID-19. Kidney Int. 2020;97(5):829-38.

24. Hansrivijit P, Qian C, Boonpheng B, Thongprayoon C, Vallabhajosyula $\mathrm{S}$, Cheungpasitporn W, et al. Incidence of acute kidney injury and its association with mortality in patients with COVID-19: a meta-analysis. J Investig Med. 2020;68(7):1261-70.

25. Hirsch JS, Ng JH, Ross DW, Sharma P, Shah HH, Barnett RL, et al. Acute kidney injury in patients hospitalized with COVID-19. Kidney Int. 2020;98(1):209-18.

26. Pan X, Xu D, Zhang H, Zhou W, Wang LH, Cui XG. Identification of a potential mechanism of acute kidney injury during the COVID-19 outbreak: a study based on single-cell transcriptome analysis. Intensive Care Med. 2020;46(6):1114-6.

27. Zou X, Chen K, Zou J, Han P, Hao J, Han Z. Single-cell RNA-seq data analysis on the receptor ACE2 expression reveals the potential risk of different human organs vulnerable to 2019-nCoV infection. Front Med. 2020;14(2):185-92.

28. Adapa S, Aeddula NR, Konala VM, Chenna A, Naramala S, Madhira BR, et al. COVID-19 and renal failure: challenges in the delivery of renal replacement therapy. J Clin Med Res. 2020;12(5):276-85.

29. Raza A, Estepa A, Chan V, Jafar MS. Acute renal failure in critically ill COVID-19 patients with a focus on the role of renal replacement therapy: a review of what we know so far. Cureus. 2020;12(6):e8429. doi: 10.7759/ cureus.8429.

Received December 14,2020 Accepted in revised form March 5, 2021 